NASA Technical Memorandum 107272

AIAA-96-2586

\title{
High Stability Engine Control (HISTEC)
}

John C. DeLaat

Lewis Research Center

Cleveland, Ohio

Robert D. Southwick and George W. Gallops

United Technologies Corporation

Pratt \& Whitney

West Palm Beach, Florida

Prepared for the

32nd Joint Propulsion Conference cosponsored by AIAA, ASME, SAE, and ASEE

Lake Buena Vista, Florida, July 1-3, 1996

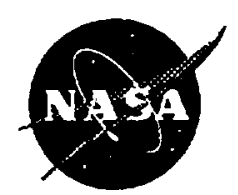

National Aeronautics and Space Administration 



\title{
HIGH STABILITY ENGINE CONTROL (HISTEC)
}

\author{
John C. DeLaat \\ NASA Lewis Research Center \\ 21000 Brookpark Road \\ Cleveland, Ohio 44135 \\ Robert D. Southwick, George W. Gallops \\ United Technologies Corporation \\ Pratt \& Whitney \\ P.O. Box 109600 \\ W. Palm Beach, Florida 33410
}

\begin{abstract}
Future aircraft turbine engines, both commercial and military, must be able to successfully accommodate expected increased levels of steady-state and dynamic engine-face distortion. The current approach of incorporating a sufficient component design stall margin to tolerate these increased levels of distortion would significantly reduce performance. The objective of the High Stability Engine Control (HISTEC) program is to design, develop, and flight demonstrate an advanced, high-stability, integrated engine control system that uses measurement-based, real-time estimates of distortion to enhance engine stability. The resulting distortion tolerant control reduces the required design stall margin, with a corresponding increase in performance and decrease in fuel burn. The HISTEC concept, consisting of a Distortion Estimation System and a Stability Management Control, has been designed and developed. The Distortion Estimation System uses a small number of high-response pressure sensors at the engine face to calculate indicators of the type and extent of distortion in real time. The Stability Management Control, through direct control of the fan and compressor pressure ratio, accommodates the distortion by transiently increasing the amount of stall margin available based on information from the Distortion Estimation System. Simulation studies have shown the HISTEC distortion tolerant control is able to successfully estimate and accommodate time-varying distortion. Currently, hardware and software systems
\end{abstract}

Copyright (c) 1996 by the American Institute of Aeronautics and Astronautics, Inc. No copyright is asserted in the United States under Title 17, U.S. Code. The U.S. Government has a royalty-free license to exercise all rights under the copyright claimed herein for government purposes. All other rights are reserved by the copyright owner. necessary for flight demonstration of the HISTEC concept are being designed and developed. The HISTEC concept will be flight tested in early 1997.

\section{INTRODUCTION}

Future aircraft turbine engines, both commercial and military, must be able to successfully accommodate expected increased levels of steady-state and dynamic engine-face distortion. Advanced tactical aircraft are likely to use thrust vectoring for enhanced aircraft maneuverability. As a result, the propulsion system will see more extreme aircraft angle-of-attack and sideslip levels than currently encountered with present-day aircraft. Also, the mixed-compression inlets needed for the High Speed Civil Transport (HSCT) will likely encounter disturbances similar to those seen by tactical aircraft in addition to planar pulse, inlet buzz, and high distortion levels at low flight speed and off-design operation. The result of these increased levels of distortion is generally a decrease in propulsion systems performance, and more importantly, a lessening of the stable flow range of the compressor. ${ }^{1}$ Current gas turbine engine design practice is to base fan and compressor stall margin requirements on the worst case stack-up of destabiliizing factors which include external factors such as inlet distortion as well as internal factors such as large tip clearances (Fig. 1a). A stability audit is defined and maintained during the development process to account for the effects of each known destabilizing factor (D1...D5 in Fig. 1b). The stability audit stacks up the worst case stall margin losses from each of the known factors, adds margin for engine-toengine variability, and assures that fan and compressor have some remaining stall margin under this worst case stack-up. However this approach, especially in the case of future engines with increased levels of distortion, 


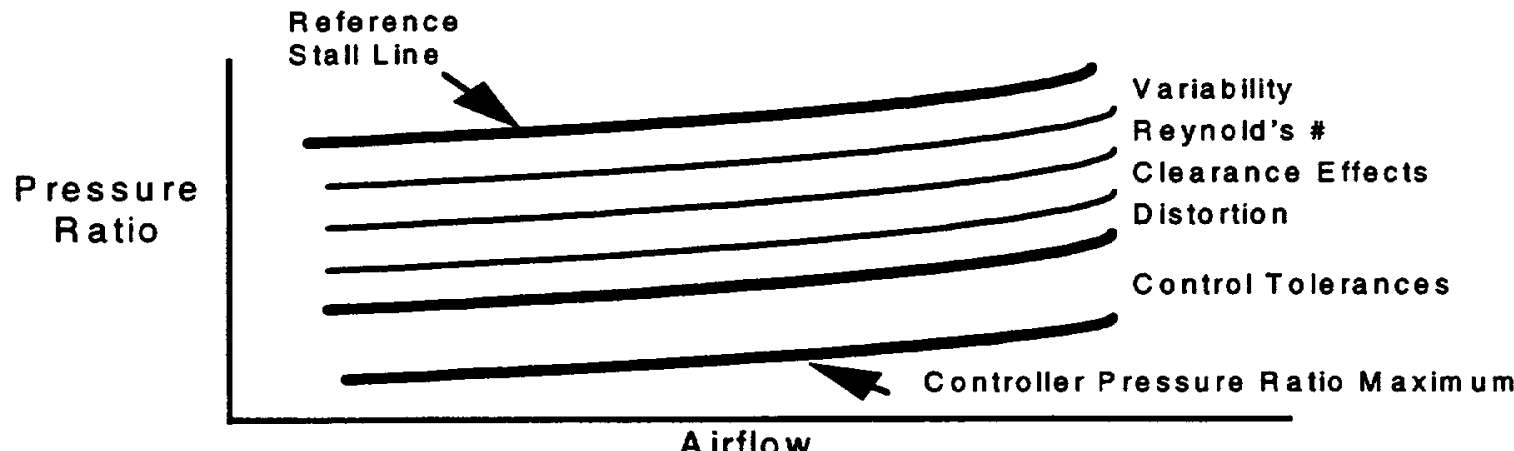

(a) Stall Margin Requirements

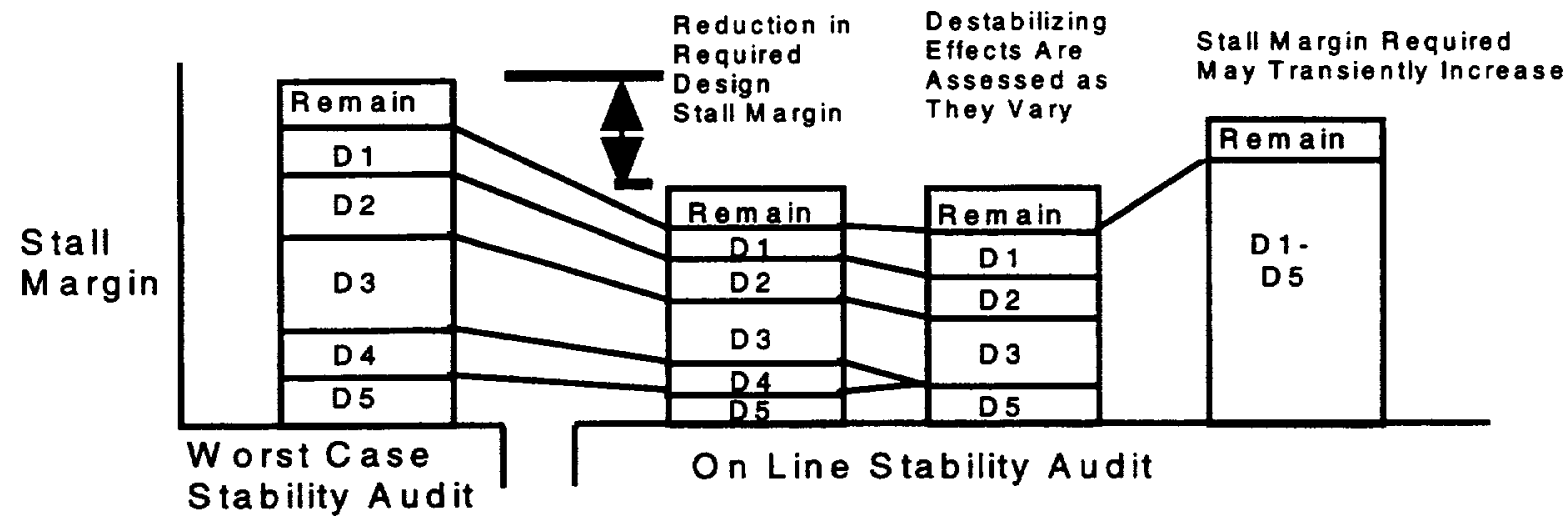

(b) Stability Audit

\section{Figure 1 - Distortion Tolerant Control Reduces Design Stall Margin Requirement}

results in an increase in design stall margin requirement with a corresponding reduction in performance and/or increase in weight.

The NASA Lewis Research Center is currently pursuing two research approaches which were confirmed beneficial by NASA's aircraft engine customers during the Advanced Control Concepts study sponsored by NASA. ${ }^{2.3,4}$ The far-term approach is to increase the amount of operational stall margin available by actively controlling the onset of stall, otherwise know as active stall control or active stability control. ${ }^{5.6}$ The near-term approach is to transiently increase the stall margin requirement on-line as the destabilizing effect, in this case engine face pressure distortion, is encountered. This approach, called dynamic stall avoidance, active stall-margin control, stability management, or distortion tolerant control, allows a reduction in the required design stall margin by an amount on the order of the destabilizing impact of the distortion (Fig. 1b). An early example of this approach is the adaptive stall margin mode of the Adaptive Engine Control System (ADECS) flown on the NASA HIDEC aircraft. The ADECS adaptive stall margin mode uptrimmed engine pressure ratio (EPR) in order to increase performance for low distortion conditions. Aircraft maneuver information was used to estimate the amount of distortion present. At conditions where it was estimated that there was a high level of distortion present, EPR was adjusted downward to maintain adequate stall margin.

The distortion tolerant control approach being developed for the High Stability Engine Control (HISTEC) program, and described in this paper, builds upon the distortion estimation approach of ADECS. Through the use of a small number of engine-face pressure measurements, a more accurate estimate of the actual distortion present can be obtained. From this measurement-based distortion estimate, and estimates of other destablizing influences, an on-line stability audit requests a time-varying stall margin requirement. The engine controller then accommodates the distortion by acting upon the current stall margin requirement supplied by the on-line stability audit.

The following sections provide an overview of the HISTEC program, a discussion of the HISTEC distortion tolerant control approach, and results to date 


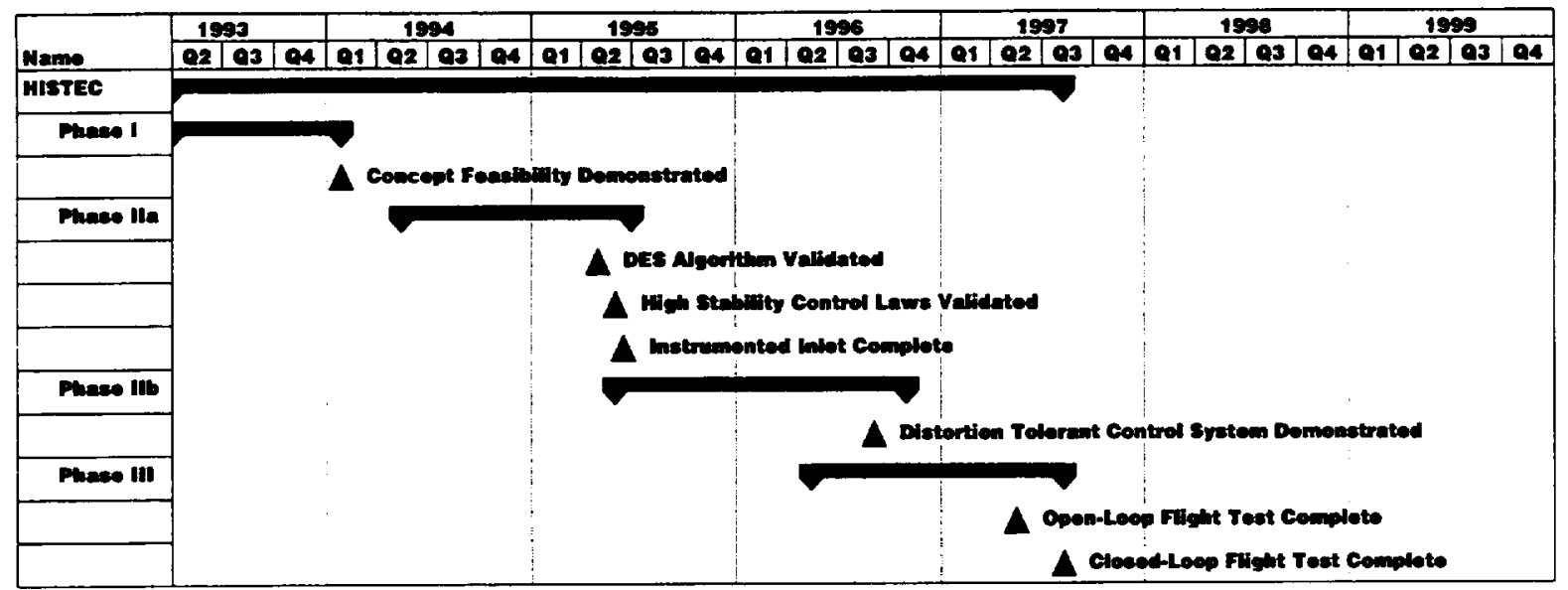

Figure 2 - HISTEC Program Timeline

of the development and evaluation of the HISTEC algorithms for aircraft turbine engine distortion tolerant control. HISTEC is scheduled to flight test on the NASA ACTIVE F-15 aircraft with F100-PW-229 engines at the Dryden Flight Research Center in Edwards, CA in early 1997.

\section{HIGH STABILITY ENGINE CONROL (HISTEC) PROGRAM OVERVIEW}

The objective of the High Stability Engine Control (HISTEC) program is to design, develop, and flight demonstrate an advanced, high-stability, integrated engine control system which uses measurement-based real-time estimation of distortion to enhance engine stability. The HISTEC program consists of three phases. Phase I - Algorithm Development, Phase II Concept Validation and System Development, and Phase III - Engine/Flight Demonstration. A timeline for the program is shown in Figure 2. During Phase I, completed in 1994, the requirements for the HISTEC distortion tolerant control system were defined, the algorithms for estimating distortion were developed and validated, the control modes necessary for distortion accommodation were designed, and initial testing to help specify the necessary HISTEC hardware/software for flight test was accomplished. ${ }^{8}$ During Phase II, the current phase, the integrated Distortion Estimation System (DES) algorithms and distortion accommodation algorithms (High Stability Control Laws) have been designed and validated. Also during Phase II, the instrumented inlet with HISTEC sensors has been fabricated and the hardware/software systems necessary for flight test are being developed. At the end of Phase II, valid operation of these hardware/software systems will be demonstrated. During Phase III, the control algorithms will be ground engine tested and the full distortion tolerant control system will be demonstrated in flight on the ACTIVE F-15. The flight test will demonstrate first "open-loop" (distortion estimation only) and then "closed-loop" (including distortion accommodation) functionality.

\section{HISTEC APPROACH}

The HISTEC approach includes two major functional elements: A Distortion Estimation System (DES) and Stability Management Control (SMC) (Fig. 3).

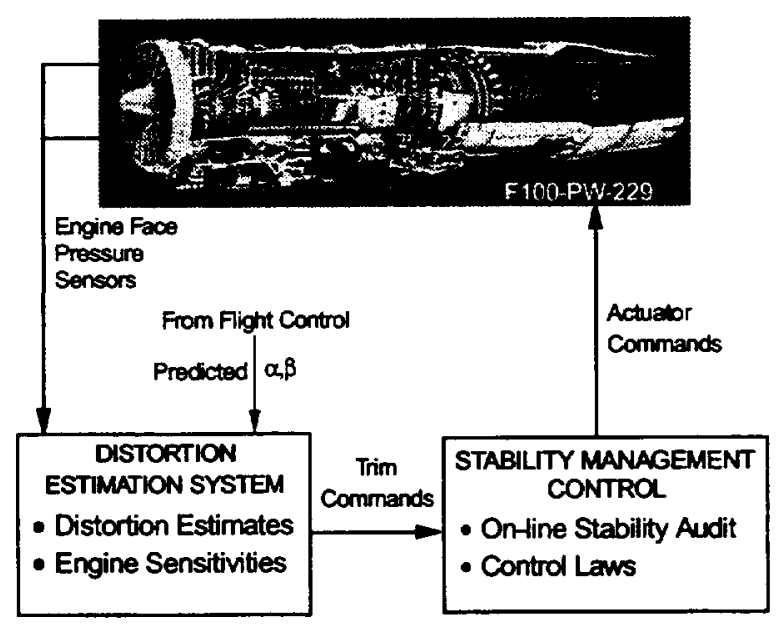

Figure 3 - HISTEC Distortion Tolerant Control

\section{Distortion Estimation System (DES)}

The DES is an aircraft mounted, high speed processor that estimates the amount and type of distortion present and the impact on the propulsion system of that distortion. The DES algorithms follow the basic concepts of traditional stability audit methodology.,10 This methodology consists of 


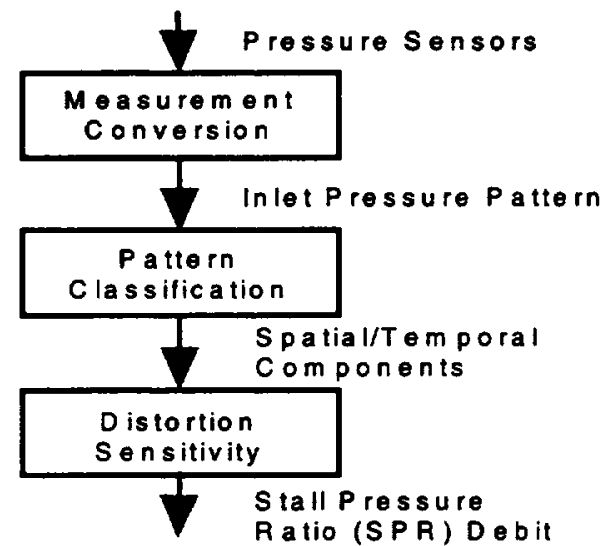

Figure 4 - Traditional Stability Audit Methodology

standards for measurement, pattern classification, and computation of stability debits (Fig. 4), and relies on the key assumption of superposition of stability debits for individual circumferential, radial, and planar dynamic distortion components.

A block diagram of the DES algorithms is shown in Figure 5. The DES uses a small number of high response pressure measurements at the engine face with a production-suitable design to calculate in real time the indicators of type and extent of distortion. Five sensors are located at the outer diameter of the engine face, and five sensors, averaged to a single measurement, are at the inner diameter. The use of engine-face pressure measurements provides a higher fidelity estimate of distortion than the maneuver-information-only approach of ADECS, and is independent of the particular engine installation.

A Fourier transform formulation of the distortion classification allows implementation of the distortion estimation using digital signal processing techniques. Spatial Fourier transforms are used to classify the circumferential, radial, and planar components of the inlet pressure patterns. The circumferential pattern is assumed fit by the Fourier series:

$$
\begin{gathered}
P(\theta)=a_{0}+a_{1} \cos \theta+b_{1} \sin \theta+ \\
a_{2} \cos 2 \theta+b_{2} \sin 2 \theta
\end{gathered}
$$

where $\theta$ is circumferential position. For five circumferential measurement locations, the 0 th, 1 st, and 2nd modes can be described. The five coefficients $\left(a_{0}, a_{1}, a_{2}, b_{1}, b_{2}\right)$ are determined by simultaneously solving the above equation for each measurement location. The coefficients are then used to define complex spatial intensities for each circumferential mode that describe the magnitude and orientation of each mode. The radial pressure profile is assumed fit by the Fourier sine series:

$$
P(\phi)=r_{0}+r_{1} \sin \phi+r_{3} \sin 3 \phi
$$

where

$$
\phi=\pi\left(R_{0}^{2}-R^{2}\right) / 2\left(R_{0}^{2}-R_{I}^{2}\right)
$$

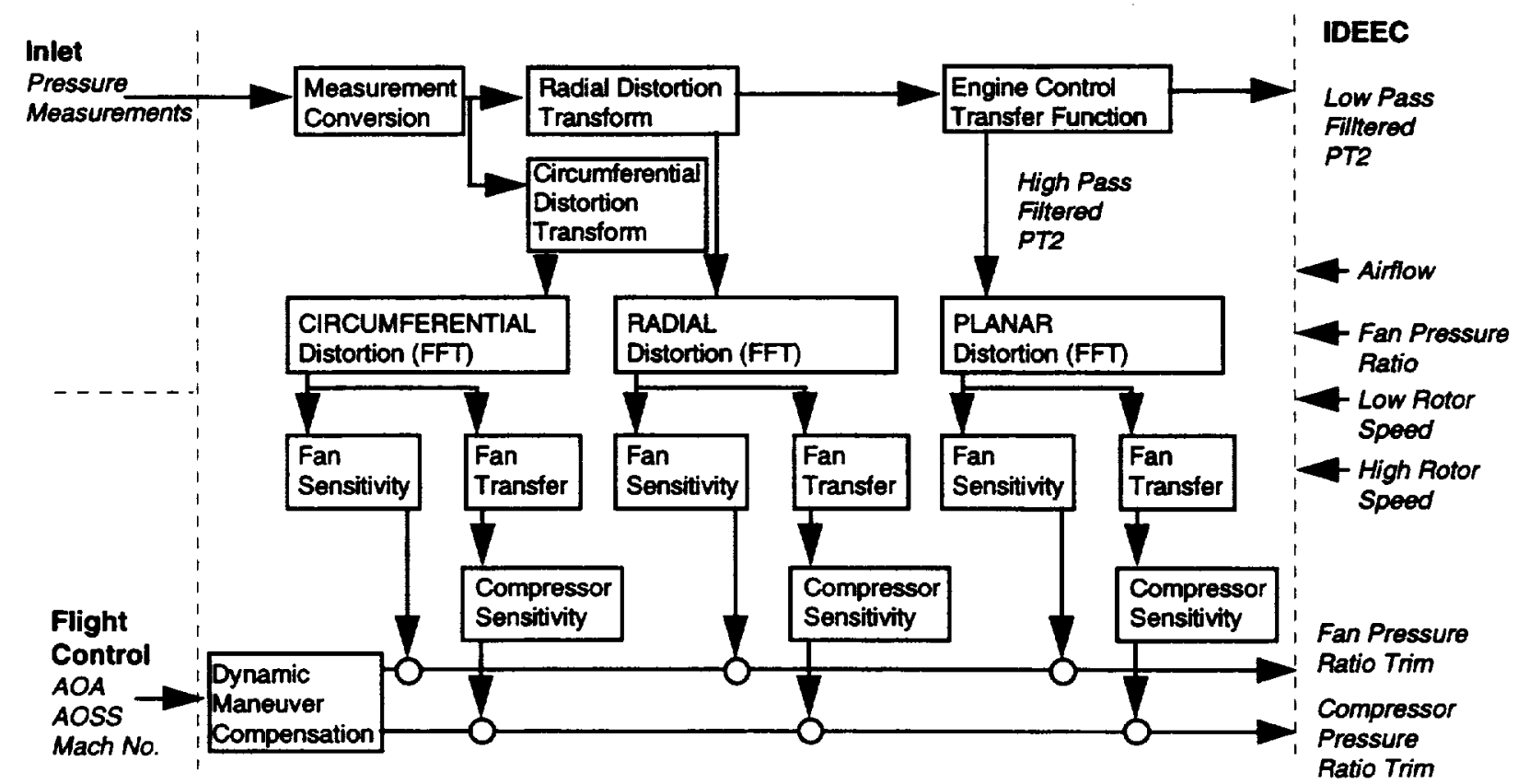

Figure 5 - Distortion Estimation System Block Diagram 
and $R$ is the flowpath radius, with $R_{0}$ and $R_{I}$ the outer and inner flowpath radii respectively. The HISTEC inlet configuration provides only two radial measurement positions (inner average, outer average) that normally would allow computation of only the first mode. To improve accuracy for the HISTEC inlet, an auxiliary equation is derived from the relationship between the first and third modes based on a priori observation of the inlet characteristics:

$$
r_{3}=f\left(r_{1}\right)
$$

As with the circumferential pressure pattern, the three coefficients $\left(r_{0}, r_{1}, r_{3}\right)$ can be determined by simultaneous solution of the equations ( 3 ) and (4) and can then be used to define the spatial intensities for each radial mode. The instantaneous face average pressure:

$$
P_{12}=r_{0}+(2 / \pi)\left(r_{1}+r_{3} / 3\right)
$$

is used in the calculation of the radial intensities. In addition, the high frequency component of $P_{0}$ is used for planar distortion computations. The low frequency component of $P_{t_{2}}$ can be used for engine pressure ratio control. "High frequency" and "low frequency" are a function of the controller bandwidth.

The dynamic behavior of the instantaneous spatial patterns is characterized by performing a temporal Fourier transform of the instantaneous spatial patterns over approximately 0.5 seconds. The resulting temporal intensity describes the magnitude, and for the circumferential patterns the orientation and translation, of the pressure pattern.

Once the distortion components are characterized as temporal intensities, these intensities are simply multiplied by an appropriate frequency domain distortion sensitivity function to arrive at a fan and compressor pressure ratio surge margin debit or pressure ratio limit trim. These sensitivity functions have been derived somewhat qualitatively by curvefitting available inlet/engine test data.

Because the response of the engine and control is of lower bandwidth than the distortion phenomenon and because there is an additional delay for the distortion estimation algorithm computations equal to the number of samples required by the temporal Fourier transforms $(\sim 0.5 \mathrm{sec})$, the DES also uses maneuver information consisting of angle-of-attack and sideslip from the flight control to anticipate high inlet distortion conditions. Dynamic compensation using the maneuver information is applied to the fan and compressor ratio limit trims.
The dynamic compensation provides a pressure ratio debit look-ahead capability early in a maneuver until the measurement-based debit becomes available approximately 0.5 seconds later. From the measurements and from the maneuver information, the DES determines the effects of the distortion on the propulsion system and the corresponding engine match point necessary to accommodate it.

Further details on the distortion estimation algorithms can be found in Reference 8.

\section{Stability Management Control (SMC)}

The output of the DES consists of fan and compressor pressure ratio trim commands which are then communicated to the SMC. The SMC is contained in the engine mounted Improved Digital Electronic Engine Control (IDEEC) and includes advanced control laws for direct control of fan and compressor transient operating line (pressure ratio). These advanced control laws, with a multivariable design, have the potential for higher bandwidth for more precise control of engine match. For HISTEC, the SMC accommodates distortion using only the production actuators for nozzle area (Aj), main burner fuel flow (Wf), compressor inlet variable vanes (CIVV) and rear compressor variable vanes (RCVV). The SMC performs an on-line stability audit for the fan and compressor to establish a baseline

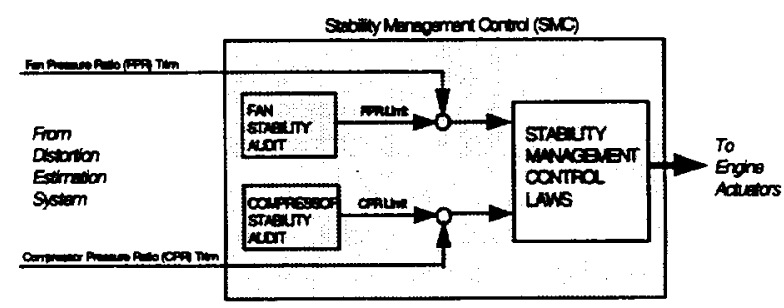

Figure 6 - Distortion Accommodation in the Stability Management Control

pressure ratio limit request for the fan and compressor. As shown in Figure 6, the pressure ratio trim commands from the DES modify the baseline pressure ratio limits computed in the SMC. If needed to satisfy the pressure ratio limits, the SMC in a multivariable fashion accommodates the distortion through the production engine actuators.

The ability to measure and assess the distortion effects in real-time coupled with a high response

\footnotetext{
"The detailed control laws in the SMC were designed and developed by Pratt \& Whitney outside of the HISTEC program. For additional information, contact the authors.
} 
controller results in improved engine stability at high levels of distortion. The approach combining the DES and SMC results in a distortion tolerant control which enables a reduced design stall margin requirement with a corresponding increase in performance and decrease in fuel burn.

\section{EVALUATION RESULTS}

\section{Distortion Estimation}

During HISTEC Phase I, the DES algorithms were exercised in the presence of synthesized patterns of circumferential, radial, and planar distortion. Figures 7 and 8 show representative results. When presented
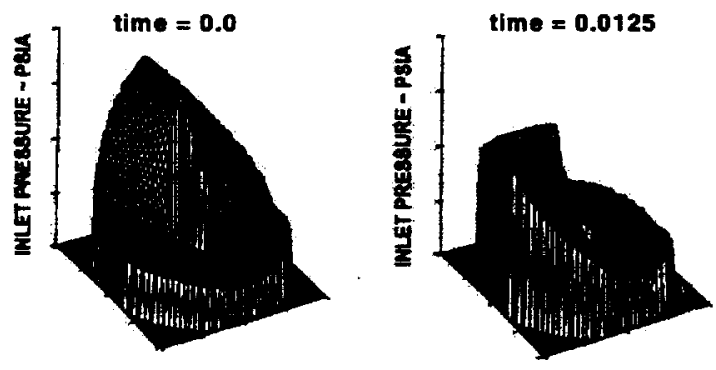

(a) Engine Face Pressure Pattern

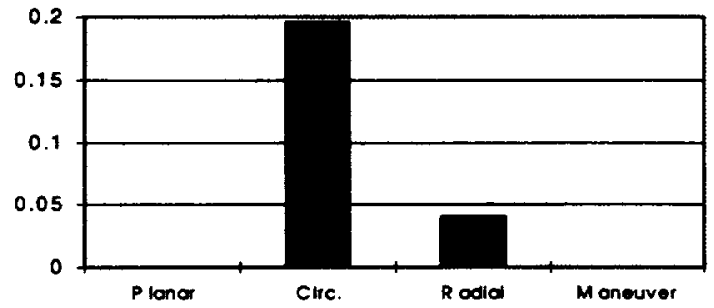

(b) Fan Pressure Ratio Debits

\section{Figure 7 - Combined Mode 1,2,3 Circumferential Distortion Rotating Synchronously At 30 Hz}

with a rotating pattern of combined 1-per-rev, 2-per-rev, and 3-per-rev circumferential distortion (Fig. 7a), the DES correctly resolves a corresponding circumferential pressure ratio debit (Fig 7 b). The small radial debit occurs because the optimum surge pressure ratio occurs at a small value of radial distortion, such that no radial distortion causes a small pressure ratio debit. When presented with an oscillating pattern of combined radial and planar distortions (Fig. 8a), the DES correctly resolves the corresponding pressure ratio debits (Fig. 8b). A total of 32 test cases were run and the DES algorithms performed as expected in all cases. Further details on the DES algorithm evaluation, the intermediate calculation results of the spatial and temporal transforms, and the sensitivity calculations for
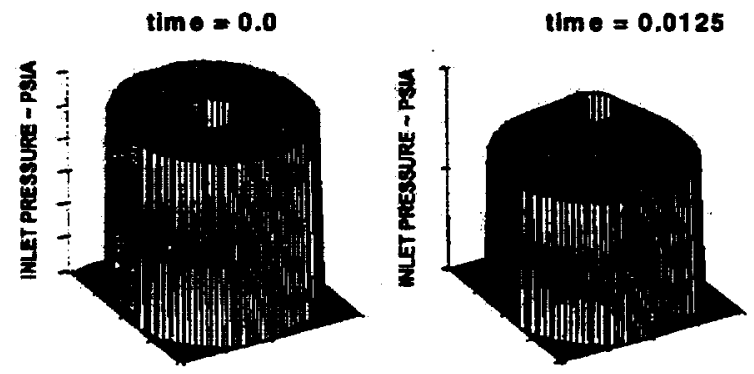

(a) Engine Face Pressure Pattern

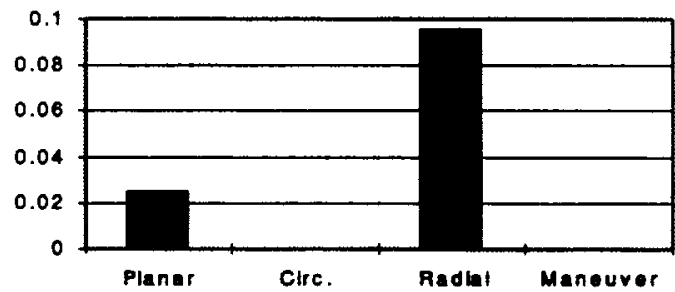

(b) Fan Pressure Ratio Debits

Figure 8 - Combined Planar And Radial Distortion Oscillating At $20 \mathrm{~Hz}$

all the test cases, can be found in the HISTEC Phase I final report.

\section{Distortion Accommodation}

Under HISTEC Phase II, integrated testing of the DES software and the SMC software has been completed. This integration testing used a detailed nonlinear aerothermal transient model of the F100-PW229 engine and an emulator of the F-15 aircraft inlet which estimates engine inlet pressures based on aircraft flight condition (mach number and altitude), angle of attack, and angle of sideslip. A total of ten test maneuvers were run to evaluate integrated HISTEC operation (Table $)$. These test maneuvers were provided by NASA Dryden Flight Research Center as representative of maneuvers with high levels of distortion. The evaluation results for three of those test maneuvers are described in the following paragraphs.

Figure 9 shows a Max Power, Max G Wind-up Turn integration test run at an altitude of 45,000 feet, Mach 1.2 (Test Case 6 in Table I). Mach number, altitude, angle of attack (ALPHA) and angle of sideslip (BETA) are shown versus time as the aircraft undergoes the maneuver. Stall margin debits computed by the DES for the fan pressure ratio or FPR are shown on the same plot for planar, circumferential, and radial distortion. 
Table I - Distortion Accommodation Test Maneuvers

\begin{tabular}{|l|l|l|l|l|}
\hline $\begin{array}{l}\text { Test } \\
\text { Case }\end{array}$ & Mach \# & $\begin{array}{l}\text { Altitude } \\
(\mathrm{ft})\end{array}$ & Power & Maneuver \\
\hline 1 & 350 & 10,000 & Max & $\begin{array}{l}\text { Max G Wind- } \\
\text { up Turn }\end{array}$ \\
\hline 2 & 0.95 & 10,000 & Mil & $\begin{array}{l}\text { Max G Wind- } \\
\text { up Turn }\end{array}$ \\
\hline 3 & 0.1 & 2,000 & Mil & Take Off \\
\hline 4 & 0.9 & 30,000 & Max & $\begin{array}{l}\text { Max G Wind- } \\
\text { up Turn }\end{array}$ \\
\hline 5 & 0.9 & 30,000 & Mil & $\begin{array}{l}\text { Pushover } \\
\text { with Sideslip }\end{array}$ \\
\hline 6 & 1.2 & 45,000 & Max & $\begin{array}{l}\text { Max G Wind- } \\
\text { up Turn }\end{array}$ \\
\hline 7 & 1.2 & 45,000 & Max & $\begin{array}{l}\text { Pushover } \\
\text { with Sideslip }\end{array}$ \\
\hline 8 & 0.7 & 45,000 & Max & $\begin{array}{l}\text { Max G Wind- } \\
\text { up Turn }\end{array}$ \\
\hline 9 & 0.7 & 45,000 & Max & $\begin{array}{l}\text { Pushover } \\
\text { with Sideslip }\end{array}$ \\
\hline 10 & 0.9 & 30,000 & Mil & $\begin{array}{l}\text { 50 deg AOA, } \\
\text { 15 deg Beta }\end{array}$ \\
\hline
\end{tabular}

The surge pressure ratio debit due to dynamic compensation using the maneuver information is represented by the maneuver debit. The total stall margin debit for the fan is the sum of the planar, circumferential, radial, and maneuver debits. This is received by the SMC as a FPR limit trim. As the maneuver commences, angle-of-attack increases, the DES calculates the distortion debits, and the corresponding FPR limit trim is computed and sent to the SMC. In a multivariable fashion, the controller accommodates the effects of distortion primarily by commanding the nozzle area open, and secondarily through the fuel flow command. The last plot (lower right in Fig. 9) shows the effect of the FPR limit trim from the DES on the FPR limit (FPRMAX). As a result of trimming FPRMAX, adequate stall margin is maintained between FPR and the fan stall line. As the maneuver is completed and ALPHA returns to zero, the fan pressure ratio limit trim is reduced thus allowing the actual fan pressure ratio to increase back to premaneuver levels. The increase in fuel flow command at the end of the transient is a function of the change in flight condition, not the distortion accommodation.

Figures 10 and 11 show the distortion tolerant control in action for two other maneuvers. Figure 10 shows a Pushover with Side Slip at 45,000 feet, Mach 0.7 (Test Case 9 in Table I). At this different flight condition, performing a different maneuver, correct distortion estimation and accommodation occurs similar to that shown in the previous figure. Figure 11 shows a maneuver synthesized at Pratt \& Whitney for very high angle of attack and side slip at 30,000 feet, Mach 0.9 (Test Case 10). Even for an angle-of-attack and an angle-of-sideslip significantly greater than will be encountered during HISTEC, correct distortion estimation and accommodation occur.

Without the HISTEC distortion tolerant control, the fan pressure ratio limit would need to be set off-line low enough to maintain adequate stall margin during the maneuver. This large stall margin would then be present even in times of low distortion and a resulting decrease in performance would occur. However, the HISTEC distortion tolerant control allowed a reduced design stall margin requirement by transiently increasing the stall margin requirement on-line when needed. Similar functionality can be shown for the compressor distortion accommodation. However, because the fan washes out most of the effects of distortion before they get to the compressor, and because the control is not operating on a compressor pressure ratio limit, no accommodation action would be seen for these particular test cases.

These results show that the HISTEC distortion tolerant control system is able to estimate inlet distortion based on a small number of engine face pressure measurements, determine the effect on engine stability, and accommodate for distortion by maintaining adequate engine surge margin. More complete results are available on request.

\section{OTHER RESULTS AND FUTURE PLANS}

During HISTEC Phase II, the Pratt and Whitney F119 Comprehensive Engine Diagnostic Unit (CEDU) has been chosen as the DES processor and an instrumented inlet case for sensing distortion has been designed and fabricated. The CEDU provides a costeffective flight-ready platform with an existing set of software design and development tools for implementing the DES for flight test. The instrumented inlet case, in addition to the DES pressure sensors, also has 35 total pressure transducers mounted into the leading edge of the inlet guide vanes and distributed across the engine face. These research sensors will allow validation of the DES sensors in flight, and will also help establish a database of dynamic distortion for future programs. The remaining hardware and software necessary to carry out the HISTEC flight demonstration are being developed during the remainder of Phase II. Detailed evaluation of all HISTEC flight hardware and 

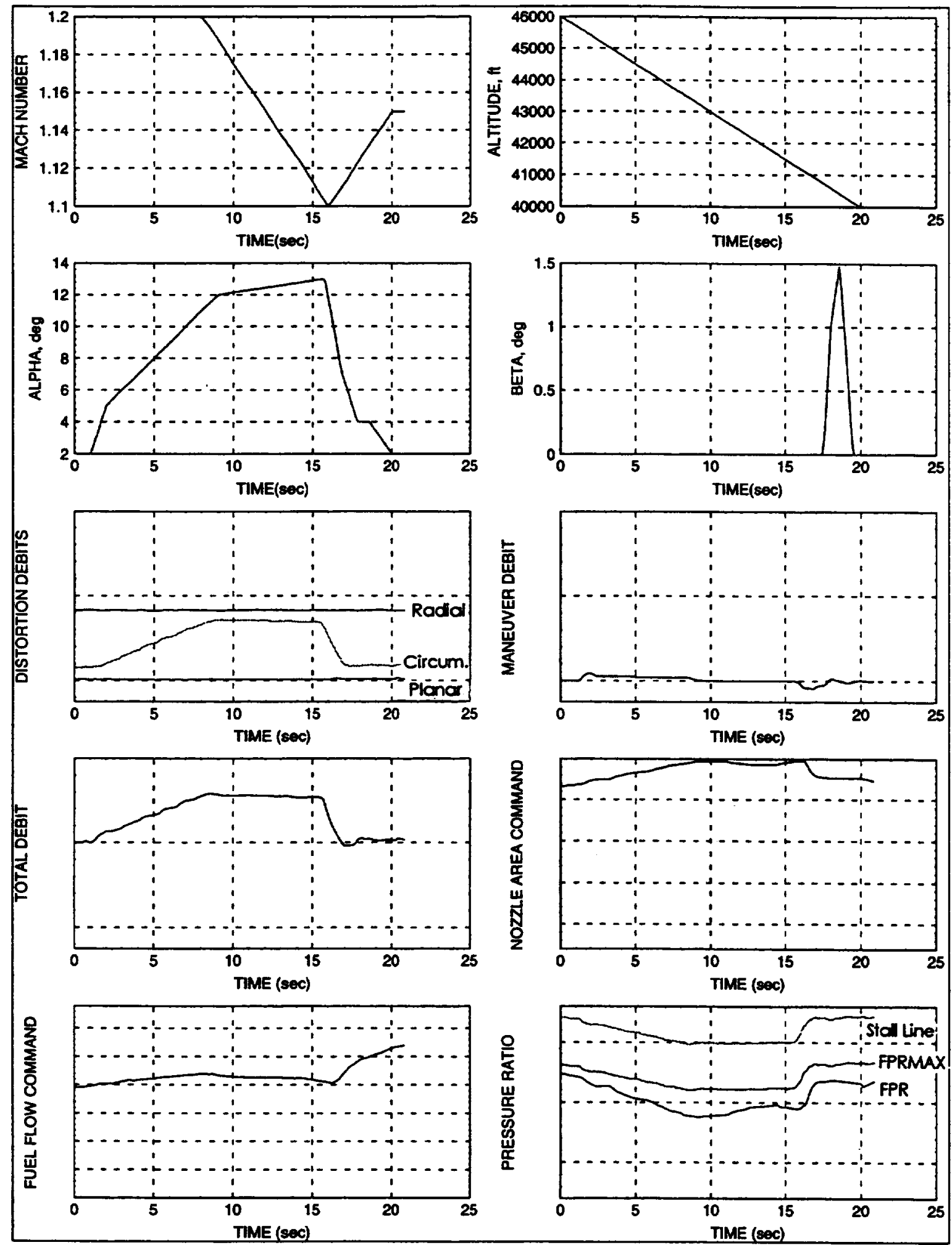

Figure 9 - Distortion Accommodation - 45K/1.2 Max Power Max G Wind-up Turn 

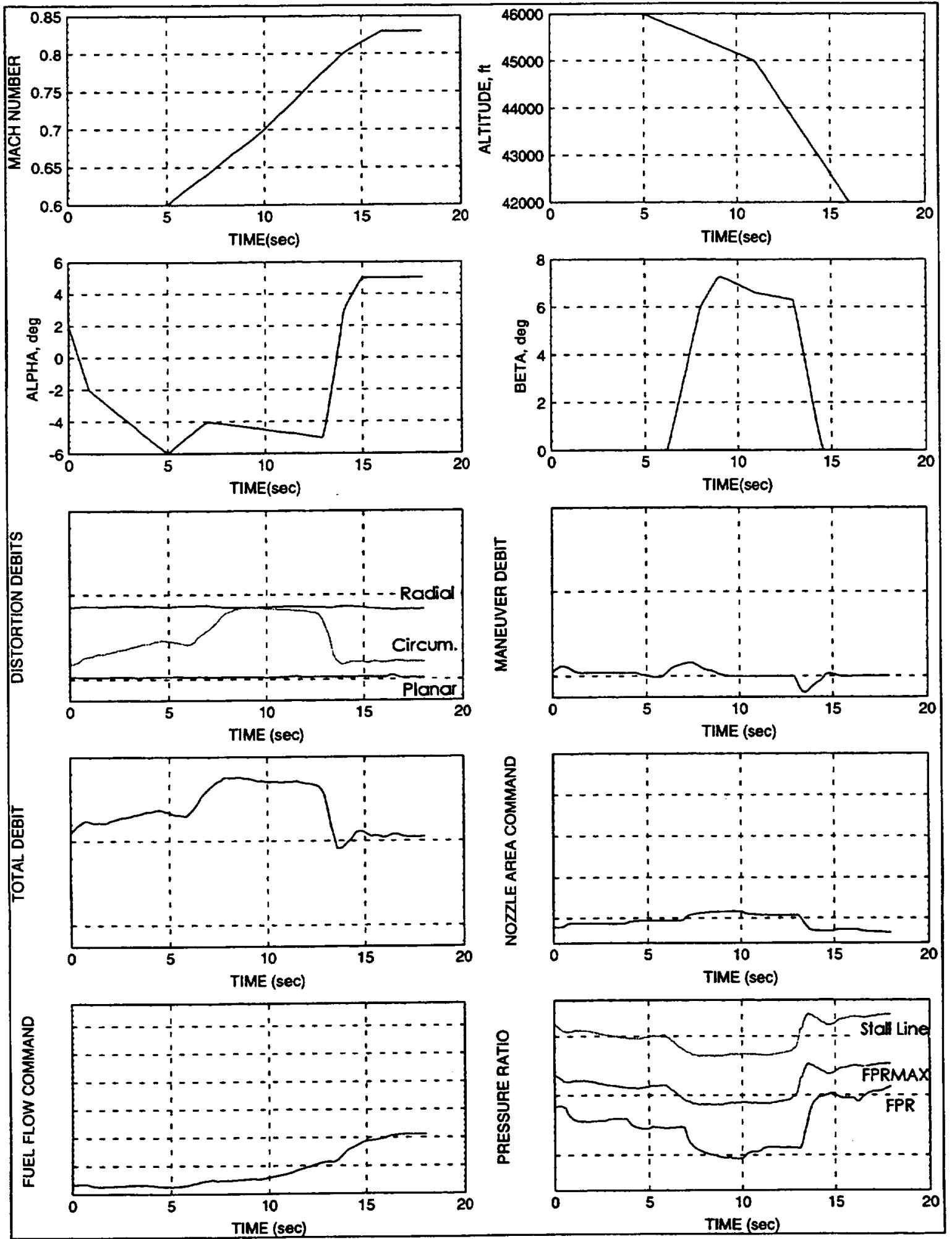

Figure 10 - Distortion Accommodation - 45K/0.7 Max Power Pushover with Side Slip 


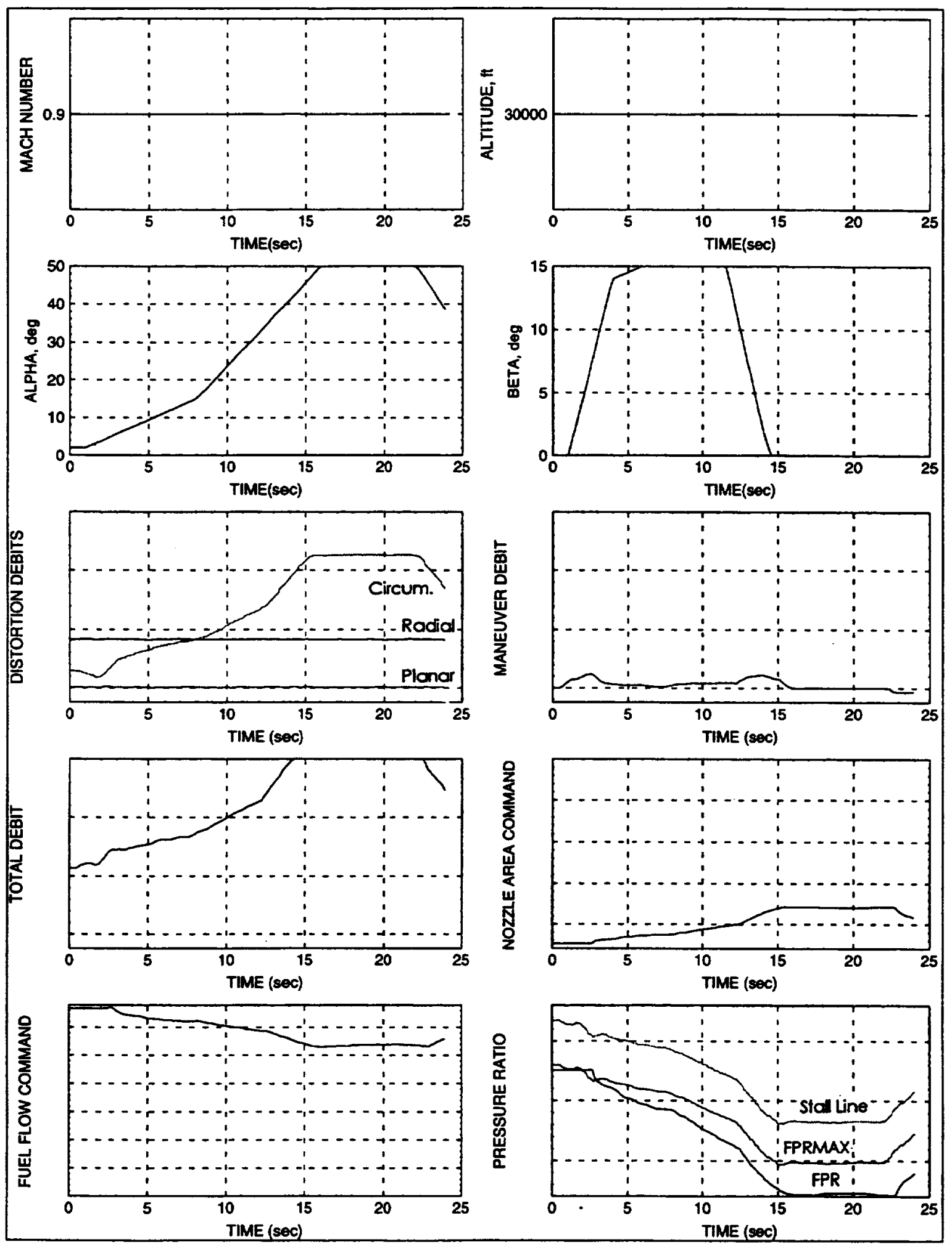

Figure 11 - Distortion Accommodation - 30K 0.9 Max Alpha/Beta Synthesized Maneuver 
software are being carried out during the remainder of 1996. HISTEC is scheduled to flight test on the ACTIVE F-15 aircraft with F100-PW-229 engines at NASA Dryden in Edwards, CA in early 1997.

\section{CONCLUSIONS}

The High Stability Engine Control (HISTEC) program is on schedule to design, develop, and flight demonstrate a distortion tolerant control system. A HISTEC-enabled decrease in design stall margin requirements will enable a significant increase in propulsion system performance and/or reduced weight. Evaluation results show that the concept will successfully accommodate inlet distortion by estimating the amount and type of distortion present based on a small number of sensors at the engine face, and then performing the necessary control action to maintain adequate stall margin. A flight demonstration of the HISTEC distortion tolerant control system, scheduled for 1997 , will significantly reduce the risk of further development of the HISTEC technologies and increases the probability of timely technology insertion in aircraft propulsion systems.

\section{References}

1. Longley, J.P.; and Greitzer, E.M.: "Inlet Distortion Effects in Aircraft Propulsion System Integration." In AGARD, Steady State and Transient Performance Prediction of Gas Turbine Engines, May 27-28, 1992

2. Ralph, J.A.: Advanced Control for Airbreathing Engines, Volume 1, Pratt \& Whitney." NASA CR 189203, July 1993.

3. Bough, R.M.: Advanced Control for Airbreathing Engines, Volume 3, Allison Gas Turbine." NASA CR 189205 , July 1993

4. Ouzts, P.J.; Lorenzo, C.F.; and Merrill, W.C.: "Screening Studies of Advanced Control Concepts for Airbreathing Engines." Prepared for the 28th Joint Propulsion Conference and Exhibit, July 6-8, 1992, NASA TM 106042.

5. Eveker, K.M.; Gysling, D.L.; Nett, C.N.; and Sharma, O.P.: "Integrated Control of Rotating Stall and Surge in Aeroengines." In proceedings: SPIE's International Symposium on Aerospace/Defense Sensing \& Control and Dual-Use Photonics "AeroSense", 4/17-4/21/95. Proceedings volume 2494.
6. Berndt, R.G.; Weigl, H.J.; Paduano, J.D.; and Epstein, A.H.: "Experimental Techniques for Actuation, Sensing and Measurement of Rotating Stall Dynamics in High Speed Compressors." In proceedings: SPIE's International Symposium on Aerospace/Defense Sensing \& Control and Dual-Use Photonics "AeroSense", 4/17-4/21/95. Proceedings volume 2494.

7. Myers, L.P.; Walsh K.R.: "Performance Improvements of an F-15 Airplane With an Integrated Engine-Flight Control System." Prepared for the AIAA Fourth Flight Test Conference, May 18-20, 1988, NASA TM 100431.

8. Southwick, Robert D.; Gallops, George W.; Larkin, Louis J.; Sobanski, Kurt J.: "High Stability Engine Control (HISTEC) Phase I: Algorithm Development, Volume I: Final Report and Appendix A." NASA CR 198399, September 1995. (Permission to use this material was granted by Sanjay Garg, June 1996.)

9. Society of Automotive Engineers: "Inlet Total Pressure Condiderations for Gas Turbine Engines", Aerospace Information Report (AIR) 1419, 1983.

10. Society of Automotive Engineers: "Gas Turbine Engine Inlet Flow Distortion Guidelines", Aerospace Recommended Practice (ARP) 1420, 1978. 


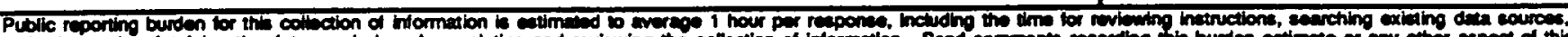

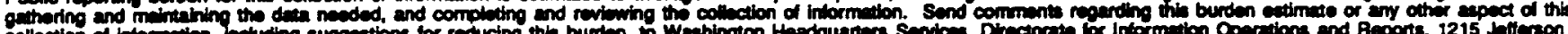

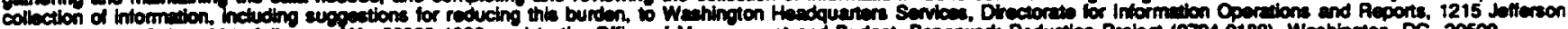

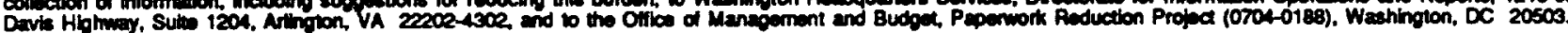

\begin{tabular}{l|l|l|} 
1. AGENCY USE ONLY (Leave blank) & 2 Ri:POAT DATE & 3. FEPOFT TYPE AND DATES COVEAED
\end{tabular}

\begin{tabular}{|l|l|l} 
June 1996 & Technical Memorandum
\end{tabular}

4. TITE AND SUBTILE

5. FUNDING NUMBERS

High Stability Engine Control (HISTEC)

6. AUTHOR(S)

WU-505-62-50

John C. DeLaat, Robert D. Southwick, and George W. Gallops

7. PERFOAING ORGANIZATION NAME(S) AND ADDRESS(ES)

8. PERFoRIMNG ORGANIZATION REPOFT NUMBER

National Aeronautics and Space Administration

Lewis Research Center

Cleveland, Ohio 44135-3191

E-10339

9. SPONSOPUNGMONTOPUNG AGENCY MAME(S) AND ADDPESS(ES)

10. SPONSORAMMONTORING AGENCY REPOAT MUNBER

National Aeronautics and Space Administration

Washington, D.C. 20546-0001

NASA TM-107272

AIAA-96-2586

11. SUPPLEMENTAAY NOTES

Prepared for the 32nd Joint Propulsion Conference cosponsored by AIAA, ASME, SAE, and ASEE, Lake Buena Vista, Florida, July 1-3, 1996. John C. DeLaat, NASA Lewis Research Center, Robert D. Southwick and George W. Gallops, United Technologies Corporation, Pratt \& Whitney, P.O. Box 109600, West Palm Beach, Florida 33410. Responsible person, John C. DeLaat, organization code 2530, (216) 433-3744.

12a. DISTPIBUTONYAVAILABILTY STATEMENT 126. DISTPaEUTION COOE

Unclassified -Unlimited

Subject Category 07

This publication is available from the NASA Center for AeroSpace Information, (301) 621-0390.

13. ABSTRACT (Maximum 200 words)

Future aircraft turbine engines, both commercial and military, must be able to successfully accommodate expected increased levels of steady-state and dynamic engine-face distortion. The current approach of incorporating a sufficient component design stall margin to tolerate these increased levels of distortion would significantly reduce performance. The objective of the High Stability Engine Control (HISTEC) program is to design, develop, and flight demonstrate an advanced, high-stability, integrated engine control system that uses measurement-based, real-time estimates of distortion to enhance engine stability. The resulting distortion tolerant control reduces the required design stall margin, with a corresponding increase in performance and decrease in fuel burn. The HISTEC concept, consisting of a Distortion Estimation System and a Stability Management Control, has been designed and developed. The Distortion Estimation System uses a small number of high-response pressure sensors at the engine face to calculate indicators of the type and extent of distortion in real time. The Stability Management Control, through direct control of the fan and compressor pressure ratio, accommodates the distortion by transiently increasing the amount of stall margin available based on information from the Distortion Estimation System. Simulation studies have shown the HISTEC distortion tolerant control is able to successfully estimate and accommodate time-varying distortion. Currently, hardware and software systems necessary for flight demonstration of the HISTEC concept are being designed and developed. The HISTEC concept will be flight tested in early 1997.

14. SUBJECT TERISS

Aircraft engines; Engine control; Flow distortion; Stability augmentation 15. NURBER OF PAGES 13

16. PRICE CODE

A03

\begin{tabular}{l|c}
\hline $\begin{array}{c}\text { 17. SECUATY CLASSIFICATION } \\
\text { OF REPORT } \\
\text { Unclassified }\end{array}$ & $\begin{array}{c}\text { 18. SECURTY CLASSIFICATION } \\
\text { OF THIS PAGE } \\
\text { Unclassified }\end{array}$ \\
\hline
\end{tabular}

19. SECUATY CLASSIFICATION OF AEstRMCT Unclassified 


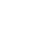




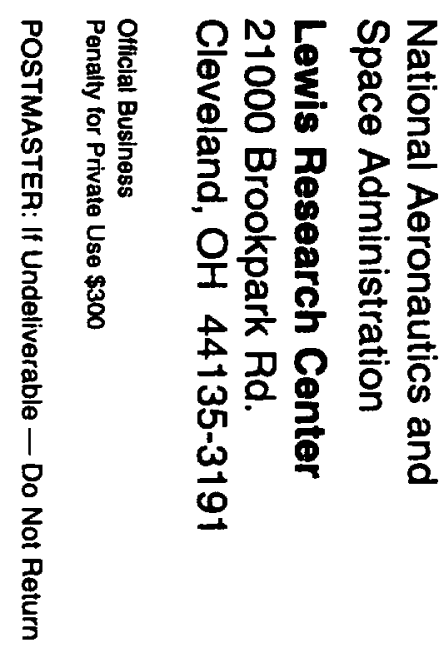

